\title{
Trial Summary Parameter Value
}

National Cancer Institute

\section{Source}

National Cancer Institute. Trial Summary Parameter Value. NCI Thesaurus. Code C83447.

A factor assigned to a trial summary boundary. 